\title{
MRI of Tibialis Anterior Skeletal Muscle in Myotonic Dystrophy Type 1
}

\author{
Chantal Coté, Bassem Hiba, Luc J. Hebert, Christophe Vial, \\ Jean François Remec, Marc Janier, Jack Puymirat
}

\begin{abstract}
Objective: The aim of this study was to evaluate whether magnetic resonance imaging (MRI) can be used as a noninvasive approach to assessment of disease severity and muscle damage in Myotonic Dystrophy type 1 (DM1). Methods: The MRI findings in legs of 41 patients with DM1 were evaluated with respect to the tibialis anterior (TA) skeletal muscle impairment. Magnetic resonance imaging findings were compared with TA strength measurements obtained by quantitative manual testing, duration of the disease and with the length of the CTG repeats. Results: Muscle MRI abnormalities were observed in $80 \%$ of DM1 patients, ranging from edema-like abnormalities alone to severe atrophy / fatty replacement. Edema-like abnormalities seem to be an earlier MRI marker of the disease. Fatty infiltration/atrophy correlated with the TA muscle force $(r=0.95)$, the severity $(P=0.00001)$ of the disease but not with the duration of the disease $(P=0.3)$ or the length of the CTG repeats $(\mathrm{P}>0.10)$, measured in peripheral leukocytes. Evaluation of other muscles of the legs revealed that the medial gastrocnemius and soleus muscles were the most frequently and severely affected muscles, while tibialis posterior muscles were relatively spared. Edema-like abnormalities are most frequently observed in the skeletal muscles of the anterior compartment. Conclusion: Muscle MRI is helpful to depict muscle abnormalities but does not seem to be a reliable indicator of skeletal muscle involvement in DM1 since the decrease in TA muscle force is not correlated with MRI abnormalities in some patients.
\end{abstract}

RÉSUMÉ: IRM du jambier antérieur dans la dystrophie myotonique de type 1. Objectif : Le but de cette étude était d'évaluer si l'IRM peut être utilisée comme démarche non effractive dans l'évaluation de la sévérité de la maladie et du dommage musculaire dans la dystrophie myotonique de type 1 (DM1). Méthodes : Les observations à l'IRM faites au niveau des jambes de 41 patients atteints de DM1 ont été évaluées pour déterminer l'atteinte du jambier antérieur (JA). Ces observations ont été comparées aux mesures de la force du JA obtenues par évaluation manuelle quantitative, la durée de la maladie et la longueur des répétitions CTG. Résultats : Des anomalies ont été observées à l'IRM du JA chez 80\% des patients atteints de DM1, allant d'anomalies ressemblant à de l'œdème seulement à de l'atrophie sévère ou une infiltration graisseuse. Les anomalies ressemblant à de l'œdème semblent constituer un marqueur plus précoce de la maladie. Il existait une corrélation entre l'infiltration graisseuse et l'atrophie et la force musculaire du JA (r $=0,95)$, la sévérité de la maladie $(\mathrm{p}=0,00001)$, mais non avec la durée de celle-ci $(\mathrm{p}=0,3)$ ou la longueur des répétitions CTG $(\mathrm{p}>0,10)$ mesurée dans les leucocytes périphériques. L'évaluation d'autres muscles des jambes a montré que le grastrocnémien interne et le muscle soléaire étaient les muscles les plus fréquemment et les plus sévèrement atteints alors que les jambiers postérieurs étaient relativement indemnes. Des anomalies ressemblant à de l'œdème sont observées le plus souvent dans les muscles squelettiques de la loge antérieure. Conclusion : L'IRM du muscle aide à décrire les anomalies musculaires mais elle ne semble pas constituer un indicateur fiable de l'atteinte du muscle squelettique dans la DM1 étant donné que la diminution de la force du JA n'est pas corrélée aux anomalies observées à l'IRM chez certains patients.

Can. J. Neurol. Sci. 2011; 38: 112-118

Myotonic Dystrophy type 1 (DM1) is the most common form of inherited muscular dystrophy in adults. Myotonic Dystrophy type 1 is a multisystem disease characterized by progressive muscle weakness and wasting, myotonia and many other extramuscular manifestations ${ }^{1}$. It is an inherited autosomal dominant disorder, caused by an increased number of a trinucleotide repeat (CTG) in the DMPK gene ${ }^{2-4}$. There was a good correlation between the length of the CTG repeats and the severity of the disease ${ }^{5}$. Muscle biopsies are no longer used for the diagnosis of myotonic dystrophy, which is currently based on clinical data and molecular testing. Nevertheless, muscle biopsies remain essential as outcome measure in DM1 therapeutic trials. Muscle biopsies are, however, invasive and need to be repeated at different periods of time in the same patient, during trials. There has been increasing evidence that muscle magnetic resonance imaging (MRI) may represent a suitable non-invasive method not only as a diagnostic tool for hereditary myopathies and muscular dystrophies but also in the

From the Department of Radiology (CC), Unit of Human Genetics (JP), CHUQ C.H.U.L, Quebec; National Defense of Canada (LJH), CFHS HQ -HS Delivery, Ottawa, Canada; Université Lyon 1, Faculté de médecine Lyon Nord, (BH, MJ); Service EMG et Pathologies Neuromusculaires -Hôpital Neurologique Pierre Wertheimer (CV, JFR), Lyon, France.

Received May 28, 2010. Final Revisions Submitted July 19, 2010. Correspondence to: Jack Puymirat, Centre hospitalier Université Laval (C.H.U.Q. pavillon C.H.U.L.), 2705 Blvd Laurier, Quebec, Quebec, G1V 4G2, Canada. 
assessment of the degree of muscle compromise during followup and in prediction of therapeutic response ${ }^{6-8}$.

Muscle MRI performed in DM1 patients showed a characteristic distribution of muscle involvement, ${ }^{7,9-13}$. The posterior compartment of the lower legs, was predominately affected, compared with the anterior compartment. This was a consistent finding in MRI studies in DM1. The most frequently affected muscles are the medial heads of gastrocnemius and soleus, whereas the tibialis posterior muscle is virtually spared. Magnetic resonance imaging of muscles showed fatty degeneration of different degrees in neighbouring muscles causing a mosaic pattern of muscles associated or not with edema-like changes. Comparative analysis of MRI findings with

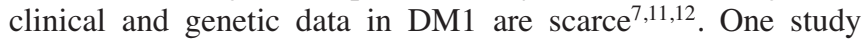
correlates muscular changes on MRI with muscular impairment of the calf muscles, estimated by manual testing ${ }^{11}$ and another demonstrated in 15 patients that MRI data were in line with clinical data evaluation according to the Muscular Impairment Rating Scale (MIRS) ${ }^{12}$. Manual muscle testing of calf muscle lacks sensitivity to detect subtle changes in muscular impairment and MIRS $^{14}$ cannot be used to establish correlation between MRI and muscle strength for a specific muscle. None of these studies, however, tried to identify MRI parameters that can be used as predictors of the severity of the disease and muscle damage.

The tibialis anterior (TA) muscle is a skeletal muscle that is prominently affected in DM $1^{1}$ and measurement of its force is easy and reproducible. In addition, it is one of the skeletal muscles that is the most frequently used for evaluation of gene or cell therapy. It represents therefore the skeletal muscle of choice to evaluate a gene therapy in patients with DM1. The aim of this study was to evaluate whether MRI can be used as a noninvasive approach to assessment of disease severity and muscle damage in DM1.

\section{Patients}

Forty-one (41) patients with DM1 (M/F:21/20; mean age 42.2 \pm 11.5 years, range 20-62 years) were included in this prospective study. Patients were recruited at the Neuromuscular clinics of the "Institut de Réadaptation en Déficience Physique de Québec" (Canada) and the Hôpital Neurologique Pierre Wertheimer de Lyon (France). Twenty-one (21) were from France and twenty (20) from Quebec. Additionally, twelve (12) age and sex- matched (average age 43 years, 6 females and 6 males), non-affected members of DM1 families confirmed by molecular analysis, without neuromuscular disease served as normal controls for signal intensity of muscles. There was no significant difference between the patients from France and Quebec for age $(39.5 \pm 13.2$ and $44.7 \pm 9.3$, mean \pm SD for patients from Quebec and France, $P=0.15)$, sex $(\mathrm{M} / \mathrm{F} 10 / 10$ and $11 / 10$ for patients from Quebec and France, $P=0.87)$ and size of the CTG repeat track $(815 \pm 459$ and $611 \pm 399$ for patients from Quebec and France, $P=0.14)$.

The diagnosis of DM1 was confirmed by molecular genetic analysis for most patients (39/41). The two patients with no molecular analysis were affected family members. The mean length of CTG repeats was $716 \pm 437$ (range 130 and 2000). The duration of disease was only available for patients from Quebec. It ranged from 5 to 43 years (average: $24.1 \pm 9.6$ years).
The study had been approved by the local CHUQ and Pierre Wertheimer hospital ethics committee and was performed in accordance with the ethical standards. Written informed consent was obtained from all patients prior to the examination.

\section{MRI examination}

Magnetic resonance imaging was performed on 1.5 Tesla magnets (GE in Quebec and Siemens in Lyon). We evaluated both legs from knee joint to distal calf using axial slices (thickness $=4 \mathrm{~mm}$, spacing $=4 \mathrm{~mm}$ ), with a surface coil. Both T1weighted SE (TR/TE=600/10ms) and dual proton-T2-weighted $\mathrm{SE}$ sequences (TR/TE $=3000 / 15 \mathrm{~ms}: 3000 / 90 \mathrm{~ms})$ with fat suppression were performed. All the slices were analyzed. The MRI score for each parameter represents the highest score obtained in slices.

A radiologist (CC) who was blinded to the clinical data carried out image analysis. Skeletal muscles were analyzed for atrophy, as seen by fatty muscle degeneration that appears as hypointense areas in T1-weighted SE sequence with fatsuppression, and also for edema-like abnormalities/ inflammatory changes, represented by hyper-intense signals in muscles in T2 weighted SE sequence with fat-suppression. For each patient, each muscle of the legs was evaluated separately, using this chart: $0=$ normal aspect on MRI, $1=$ edema-like abnormalities (hyper-intense T2 signals with fat-suppression). We use the term "edema-like abnormalities" because its significance is not well known. Increased water content may be seen with inflammation, edema and necrosis, none of which are typically seen in DM1 muscle biopsies, 2= mild atrophy with sporadic scattered fatty infiltration areas, $3=$ moderate atrophy with numerous scattered fatty infiltration areas, and $4=$ complete atrophy/fatty replacement. This chart is a modified version of a chart used in a previous study by Kornblum and $\mathrm{al}^{12}$, to include edema-like abnormalities in the scoring scheme. To obtain a total MRI score for a patient, we did a summation of the score of each separate muscle of one leg.

\section{Clinical examination}

Patients were evaluated by the same neurologist: J.P. (Quebec) and C.V. (France). Muscular impairment was defined using the five-point Muscular Impairment Rating Scale: 1, no muscular impairment; 2, minimal signs (myotonia, facial weakness, ptosis, nasal speech, jaw and temporal wasting, neck flexor weakness, no distal weakness except isolated digit flexor weakness); 3, distal weakness without proximal weakness; 4, mild to moderate proximal weakness; 5 , severe muscle weakness (Medical Research Council scale <3). For all patients, including patients from France and Quebec, a quantitative muscular testing of ankle dorsiflexion was done using a Chatillon push-pull handheld dynamometer, according to a protocol that was validated ${ }^{15}$. The outcome used was the maximal isometric muscle strength expressed in torque values (Newton meter, $\mathrm{Nm}$ ). Torque values of ankle dorsiflexion and MRI scores of tibialis anterior were used for comparison.

\section{Statistical analysis}

The pairwise relationships between variables were studied using Pearson's correlation coefficients, while the multivariate 
relationships were established using a regression model. The most important exploratory variables were selected by the stepwise and the best subset selection methods. The magnitude of differences between correlations were tested using William's T2 statistic when correlations were depended, and with the Fisher's transformation statistic when correlations were independent. Partial correlations were also used to test the significance relationships between two variables when adjusting for the effect of a third variable. Finally, the multivariate Wilk's lambda statistic was used to compare the mean scores between Quebec and France, followed by univariate T-tests statistics when significance difference was observed. More generally, the scores' distributions were compared between the two locations with the Kolmogorov-Smirnov's statistic. The same statistics were used in the comparison of men and women. All the analyses were done at $\leq 0.05$ level, using the SAS software (SAS institute, $\mathrm{NC}$, version 9.1).

\section{RESULTS}

MRI Evaluation of the Tibialis Anterior Skeletal Muscle in Myotonic Dystrophy type 1

The clinical data and MRI findings for all the skeletal muscles of the leg are summarized in Table 1. Molecular data were available for 39 patients.

There was an asymmetry of MRI muscular involvement in both legs in a majority of patients (72\%). Although the difference is often mild, in 12 patients (28\%) there was a marked difference, ranging from normal on one leg to moderate atrophy on the other leg, or from mild atrophy to severe fatty replacement. Those differences affected only a limited number of muscles, between one and three in each patient. An asymmetry of MRI abnormalities between the right and the left TA muscle was only observed in four patients (10\%). The difference was mild, ranging from normal on one leg to moderate atrophy on the other leg, or from mild atrophy to severe fatty replacement. We decide therefore to analyze the most severely affected TA muscle for each patient.

No significant differences were observed between France and Quebec MRI findings (the $t$ values were varying from 0.09 to 0.93 depending of the skeletal muscle), thus French and Quebec data have been pooled for analysis. In eight patients (19.5\%), there was no MRI abnormality in the TA muscle (Figure 1A, B). Thirty-three $(80 \%)$ patients had abnormal MRI findings in the TA (Table 2). Those abnormalities ranged from only edema-like abnormalities (Figure 1C, D; 9.7\%), fatty infiltration/atrophy (Figure 1E, F; 7.3\%) and edema-like abnormalities /atrophy/fatty infiltration (Figure $1 \mathrm{G}, \mathrm{H} ; 63 \%$ ).

For the muscles of the leg, the muscle MRI abnormalities varied greatly depending on the muscle examined but all DM1 patients had abnormal MRI findings in at least one skeletal muscle of the leg. In ten patients without MRI abnormalities or edema-like abnormalities alone in the TA muscle, there were moderate to severe MRI abnormalities in the medial or lateral gastrocnemius and/or in the soleus muscles. We also observed that muscular abnormalities in DM1 patients are not diffuse, and do not affect all muscles of a patient to the same extent (Figure 1). Table 3 summarizes the results obtained from the MRI evaluation for each muscle of the leg. Medial gastrocnemius and soleus were the most frequently and severely affected muscles in
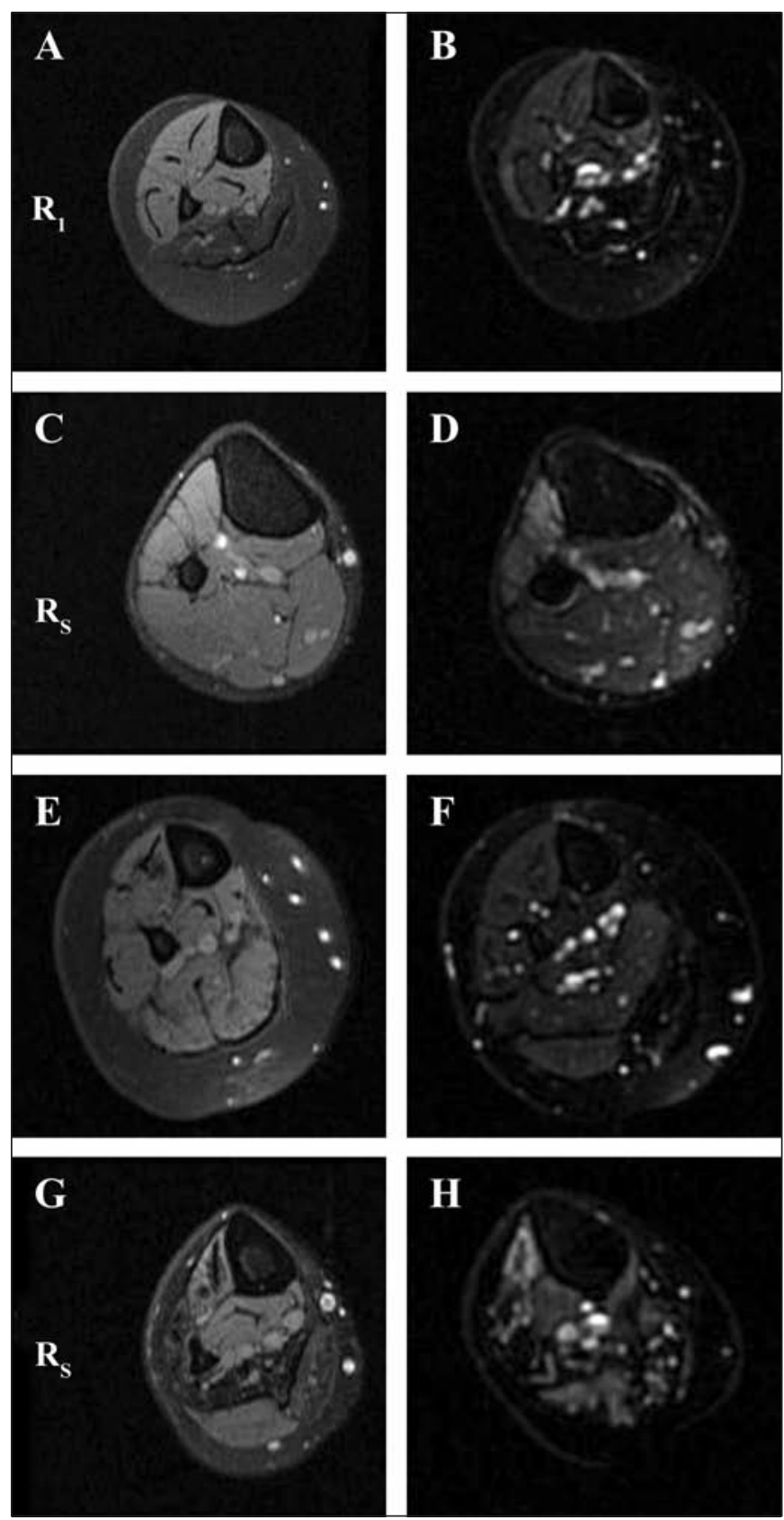

Figure 1: Typical MRI appearances in DM1 patients. (A) Axial T1weighted and (B) T2-weighted SE sequence with fat suppression of one leg of a patient with normal TA muscle on both sequences. Note that there is complete atrophy of soleus and gastrocnemius muscles in posterior compartment of the leg. In another patient, (C) axial T1weighted sequence is normal but (D) T2-weighted SE sequence with fat suppression show hyperintense signal or edema-like abnormalities of TA muscle only. (E) Axial Tlweighted SE sequence with fat suppression of a patient with partial central atrophy/fatty infiltration of TA muscle. On the T2-weighted sequence with fat-suppression $(F)$, there is no edema-like abnormalities of this muscle, so this patient presented isolated atrophy. In another patient, $(G)$ axial T1-weighted sequence also demonstrates partial atrophy of TA muscle, but there is also edema-like hyperintense signal of this muscle on the T2-weighted sequence $(H)$. This patient also presents severe atrophy of median gastrocnemius, soleus and peroneus muscles. 
Table 1: Details of Clinical and MRI findings observed in the 41 DM1 patients

\begin{tabular}{|c|c|c|c|c|c|c|c|c|c|c|c|c|c|c|c|}
\hline Patient & Sex/age & $\begin{array}{c}\text { Duration } \\
\text { (years) }\end{array}$ & $\begin{array}{l}\text { CTG } \\
\text { repeats }\end{array}$ & MIRS & $\begin{array}{c}\text { Torques } \\
\text { values }\end{array}$ & $\begin{array}{l}\text { Tibialis } \\
\text { anterior }\end{array}$ & $\begin{array}{l}\text { Extensor } \\
\text { hallucis } \\
\text { longus }\end{array}$ & $\begin{array}{l}\text { Extensor } \\
\text { digitorum } \\
\text { longus }\end{array}$ & Peroneus & $\begin{array}{c}\text { Medial } \\
\text { gastrocn. }\end{array}$ & $\begin{array}{l}\text { Lateral } \\
\text { gastrocn. }\end{array}$ & Soleus & $\begin{array}{l}\text { Tibialis } \\
\text { posterior }\end{array}$ & $\begin{array}{l}\text { Flexor } \\
\text { hallucis } \\
\text { longus }\end{array}$ & $\begin{array}{c}\text { Flexor } \\
\text { digitorum } \\
\text { longus }\end{array}$ \\
\hline 1 & $\mathrm{~F} / 46$ & 21 & 1200 & 5 & 4.6 & 4 & 4 & $1+3$ & $1+3$ & 4 & $1+3$ & 4 & $1+2$ & 4 & $1+3$ \\
\hline 2 & $\mathrm{M} / 26$ & 12 & 350 & 4 & 4.7 & $1+2$ & $1+2$ & $1+2$ & 0 & $1+2$ & 1 & 1 & 0 & 0 & 0 \\
\hline 3 & $\mathrm{M} / 34$ & 19 & 350 & 4 & 3 & $1+3$ & $1+3$ & $1+3$ & 0 & 1 & 0 & 1 & 0 & 1 & 0 \\
\hline 4 & $\mathrm{M} / 31$ & 31 & 600 & 4 & 2.7 & $1+3$ & $1+3$ & $1+3$ & 3 & 3 & 2 & 3 & 0 & 2 & 0 \\
\hline 5 & $\mathrm{M} / 41$ & 28 & 1000 & 5 & 8.5 & $1+3$ & $1+4$ & 4 & 4 & $1+4$ & $1+3$ & $1+4$ & $1+3$ & $1+4$ & $1+3$ \\
\hline 6 & $\mathrm{~F} / 46$ & 28 & 1100 & 4 & 3.7 & $1+3$ & $1+3$ & $1+3$ & $1+3$ & 4 & 3 & 4 & 1 & 4 & $1+3$ \\
\hline 7 & $\mathrm{~F} / 62$ & 43 & 1300 & 5 & 1.8 & 4 & 4 & 3 & 4 & 4 & 4 & 4 & 3 & 4 & 4 \\
\hline 8 & $\mathrm{M} / 53$ & 24 & 1300 & 3 & 6.7 & 0 & 0 & 0 & 2 & 4 & 3 & 4 & 0 & 4 & 0 \\
\hline 9 & $\mathrm{~F} / 57$ & 32 & 900 & 4 & 8.5 & 2 & 2 & 2 & 0 & 4 & 1 & 4 & 2 & 3 & 1 \\
\hline 10 & $\mathrm{~F} / 40$ & 31 & 600 & 4 & 2.7 & $1+2$ & $1+2$ & 0 & $1+2$ & 4 & $1+3$ & 4 & 1 & 3 & 1 \\
\hline 11 & $\mathrm{M} / 35$ & 25 & 1000 & 4 & 11 & $1+2$ & 2 & 2 & 1 & 1 & 0 & 1 & 0 & 1 & 1 \\
\hline 12 & $\mathrm{~F} / 55$ & 24 & 130 & 3 & 9.3 & 1 & 1 & 1 & 0 & 3 & 0 & $1+3$ & 0 & 0 & 0 \\
\hline 13 & $\mathrm{M} / 20$ & 20 & 1300 & 3 & 11 & $1+2$ & 0 & 0 & 0 & 1 & 0 & 1 & 0 & 1 & 1 \\
\hline 14 & $\mathrm{~F} / 53$ & 41 & 550 & 3 & 11.8 & 0 & 0 & 0 & 0 & 4 & 3 & 4 & 0 & 4 & 1 \\
\hline 15 & $\mathrm{M} / 22$ & 6 & 1300 & 3 & 10.7 & 1 & 1 & 1 & 1 & 0 & 0 & 1 & 0 & 1 & 1 \\
\hline 16 & $\mathrm{~F} / 25$ & 5 & 175 & 3 & 19.7 & 0 & 0 & 0 & 0 & 1 & 0 & 0 & 0 & 0 & 0 \\
\hline 17 & $\mathrm{M} / 28$ & 27 & 1400 & 3 & 17.1 & 1 & 1 & 1 & 1 & $1+2$ & 1 & 1 & 0 & 0 & 1 \\
\hline 18 & $\mathrm{M} / 34$ & 20 & 300 & 3 & 14.5 & 1 & 0 & 0 & 0 & 4 & $1+2$ & 1 & 0 & 0 & 0 \\
\hline 19 & $\mathrm{~F} / 56$ & 22 & 150 & 3 & 16.1 & 0 & 0 & 0 & 0 & 3 & 0 & 2 & 0 & 0 & 0 \\
\hline 20 & $\mathrm{~F} / 27$ & 22 & 1300 & 3 & 8.6 & 0 & 0 & 0 & 1 & 4 & 1 & $1+3$ & 0 & $1+2$ & 1 \\
\hline 21 & $\mathrm{M} / 42$ & $\mathrm{n} / \mathrm{d}$ & 600 & 3 & 11.1 & $1+2$ & 0 & 0 & 2 & 4 & 3 & 4 & 0 & 3 & 0 \\
\hline 22 & $\mathrm{~F} / 37$ & $\mathrm{n} / \mathrm{d}$ & 500 & 3 & 11.3 & 0 & 0 & 0 & 0 & 4 & 4 & 4 & 0 & 0 & 0 \\
\hline 23 & $\mathrm{~F} / 46$ & $\mathrm{n} / \mathrm{d}$ & 800 & 4 & 7.2 & $1+2$ & $1+2$ & $1+2$ & 4 & 4 & 2 & 4 & 0 & 0 & 0 \\
\hline 24 & $\mathrm{~F} / 54$ & $\mathrm{n} / \mathrm{d}$ & 650 & 4 & 4.7 & $1+3$ & $1+3$ & $1+3$ & 4 & 4 & 4 & 4 & 0 & 4 & 1 \\
\hline 25 & $\mathrm{M} / 62$ & $\mathrm{n} / \mathrm{d}$ & 367 & 3 & 8.1 & $1+3$ & 2 & 2 & 0 & 4 & 0 & 2 & 0 & 0 & 0 \\
\hline 26 & $\mathrm{~F} / 48$ & $\mathrm{n} / \mathrm{d}$ & 175 & 3 & 12.8 & 0 & 0 & 0 & 0 & 0 & 0 & 2 & 0 & 0 & 0 \\
\hline 27 & $\mathrm{M} / 42$ & $\mathrm{n} / \mathrm{d}$ & 230 & 3 & 6.7 & $1+3$ & 1 & 1 & 0 & 3 & 0 & $1+3$ & 0 & 2 & 0 \\
\hline 28 & $\mathrm{M} / 23$ & $\mathrm{n} / \mathrm{d}$ & 767 & 3 & 10 & 0 & 0 & 0 & 0 & 4 & 0 & 4 & 0 & 0 & 0 \\
\hline 29 & $\mathrm{M} / 45$ & $\mathrm{n} / \mathrm{d}$ & 800 & 3 & 7.8 & $1+3$ & $1+3$ & $1+3$ & 2 & 4 & 0 & 3 & 0 & 3 & 0 \\
\hline 30 & $\mathrm{~F} / 40$ & $\mathrm{n} / \mathrm{d}$ & $\mathrm{n} / \mathrm{d}$ & 3 & 5.3 & $1+3$ & $1+3$ & $1+3$ & 2 & 4 & 4 & 4 & 2 & 4 & 2 \\
\hline 31 & $\mathrm{M} / 51$ & $\mathrm{n} / \mathrm{d}$ & 667 & 3 & 7 & $1+3$ & $1+2$ & $1+2$ & 2 & 4 & 4 & 4 & 0 & 4 & 0 \\
\hline 32 & $\mathrm{~F} / 46$ & $\mathrm{n} / \mathrm{d}$ & 200 & 4 & 7.3 & $1+2$ & $1+2$ & $1+2$ & 0 & 0 & 0 & 0 & 0 & 0 & 0 \\
\hline 33 & $\mathrm{~F} / 57$ & $\mathrm{n} / \mathrm{d}$ & 467 & 4 & 4.2 & $1+3$ & $1+3$ & $1+3$ & $1+3$ & 4 & 4 & 4 & 0 & 3 & 0 \\
\hline 34 & $\mathrm{~F} / 48$ & $\mathrm{n} / \mathrm{d}$ & 2000 & 4 & 3.4 & $1+4$ & $1+3$ & $1+3$ & 4 & 4 & 4 & 4 & 2 & 3 & 0 \\
\hline 35 & $\mathrm{M} / 50$ & $\mathrm{n} / \mathrm{d}$ & 367 & 4 & 4.5 & $1+3$ & $1+3$ & $1+3$ & 2 & 4 & 2 & 4 & 0 & 4 & 1 \\
\hline 36 & $\mathrm{~F} / 35$ & $\mathrm{n} / \mathrm{d}$ & 733 & 4 & 5.4 & $1+3$ & $1+3$ & $1+3$ & $1+3$ & 4 & 3 & 4 & 1 & 3 & $1+3$ \\
\hline 37 & $\mathrm{M} / 32$ & $\mathrm{n} / \mathrm{d}$ & 600 & 3 & 3.9 & $1+3$ & $1+3$ & $1+3$ & 0 & $1+2$ & 0 & $1+2$ & 0 & 0 & 1 \\
\hline 38 & $\mathrm{M} / 31$ & $\mathrm{n} / \mathrm{d}$ & 867 & 4 & 3.6 & $1+3$ & $1+3$ & $1+3$ & $1+2$ & 3 & 2 & $1+3$ & 0 & 2 & 0 \\
\hline 39 & $\mathrm{M} / 56$ & $\mathrm{n} / \mathrm{d}$ & 533 & 4 & 2.7 & $1+3$ & $1+3$ & $1+3$ & 3 & 4 & 3 & 4 & 0 & 4 & 0 \\
\hline 40 & M/46 & $\mathrm{n} / \mathrm{d}$ & $\mathrm{n} / \mathrm{d}$ & 5 & 3.5 & $1+3$ & $1+3$ & $1+3$ & $1+3$ & 4 & 4 & 4 & $1+2$ & 4 & $1+2$ \\
\hline 41 & $\mathrm{M} / 42$ & $\mathrm{n} / \mathrm{d}$ & 300 & 3 & 4.9 & $1+3$ & $1+2$ & $1+3$ & 0 & 4 & 2 & $1+2$ & 0 & 0 & 0 \\
\hline
\end{tabular}

MRI score : $0=$ no abnormality, $1=$ oedema only, $2=$ mild fatty infiltration/atrophy, $3=$ moderate fatty infiltration/atrophy, $4=$ severe fatty infiltration/atrophy, $1+(1-4)=$ oedema + fatty infiltration/atrophy.

DM1 patients. In contrast, the tibialis posterior was the least affected. Flexor digitorum longus muscle was also relatively spared (44\% patients affected). All the other muscles were affected to some degree in more than half of the patients. Tibialis anterior, extensor hallucis longus and extensor digitorum longus muscles were the most affected by edema-like abnormalities (Table 1). The medial gastrocnemius and the soleus muscles were the most affected by atrophy, followed by the tibialis anterior, the flexor hallucis longus and extensor hallucis longus. In contrast, the tibialis posterior muscles were the least affected by atrophy and edema-like abnormalities.

\section{MRI and Clinical Evaluation}

No significant difference was observed for the Torque values between Quebec and Lyon, thus the data were pooled (6.44 \pm 2.9 and $8.3 \pm 4.7 \mathrm{Nm}$, mean $\pm \mathrm{SD}$ of Quebec and French values, $P=$
Table 2: Tibialis anterior muscular MRI findings in DM1

Finding Number of patients

$\begin{array}{ll}\text { No abnormalities } & 8 \\ \text { Edema only } & 4 \\ \text { Atrophy/fatty infiltration } & 3 \\ \text { Edema + atrophy/fatty infiltration } & 26\end{array}$

Edema + atrophy/fatty infiltration

26 


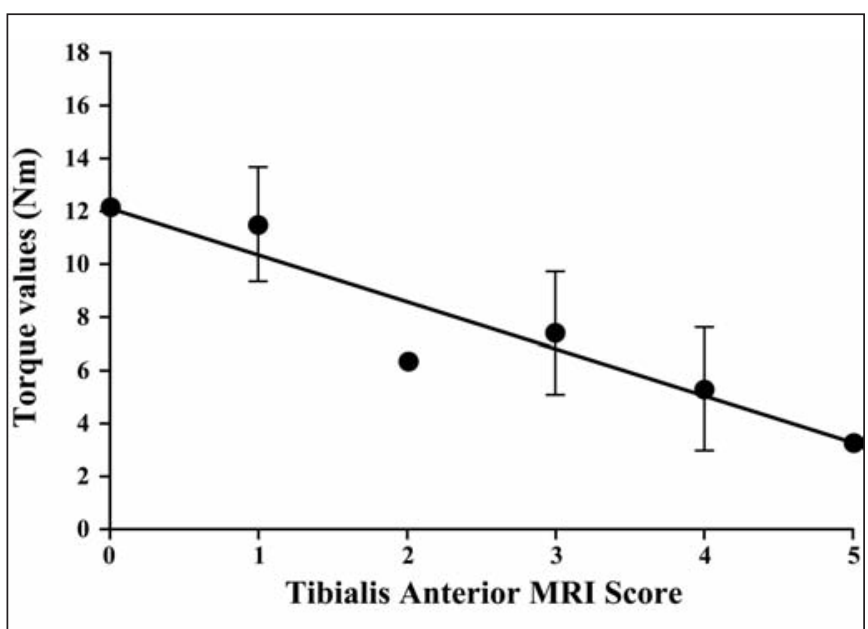

Figure 2: Negative correlation between the Tibialis Anterior MRI Score and the Tibialis Anterior Muscle Strength. Quantitative muscle strength was determined using a dynamometer type Chatillon. Results are expressed by the Torque values in Newton meter $(\mathrm{Nm})$. Linear regression $(r=0.95)$

$0.13)$. There was no effect of the sex $(P=0.9)$, age $(P=0.2)$ and the number of CTG repeat $(P=0.55)$ on TA muscle force. There was a significant negative correlation between the MRI score of the TA and the ankle dorsiflexion muscle force, as determined by quantitative muscle testing (Figure 2, regression analysis $r=$ 0.95). Two of the four patients with edema-like abnormalities only had a significant decrease in muscle strength (9.3 and 10.7 $\mathrm{Nm}$ vs $27.1 \pm 4.6 \mathrm{Nm}$, range 15.3 - 36.5 for controls). In addition, a significant decrease in TA muscle force was noted in eight patients without any MRI TA abnormalities (27.1 \pm 4.6 and $12.1 \pm 4.1 \mathrm{Nm}$, mean \pm S.D., for controls and DM1 patients without MRI abnormalities, $P=0.001)$. Finally, although there was some difference in MRI abnormalities between the right and left TA muscle, no significant difference was noted in muscle

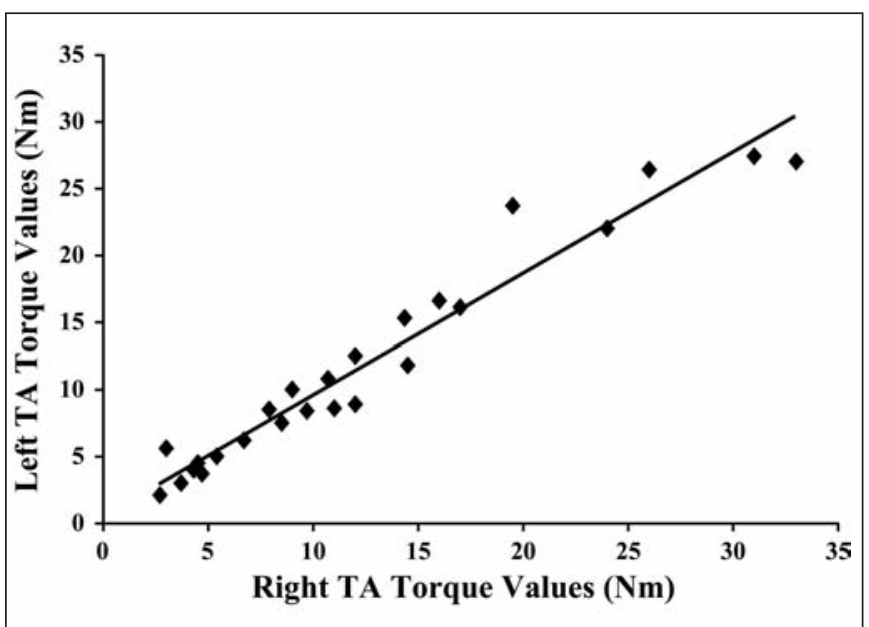

Figure 3: Correlation between the force of the right and left tibialis anterior (TA) skeletal muscle. Muscle strength was determined using a dynamometer type Chatillon. Results are expressed by the Torque values in Newton meter (Nm). Each point represent the mean of 2 evaluations performed at 3 week intervals. Each value represents the mean of 2 to 3 determinations ( 3 in case of a variation above 10\% between the 2 first measures).

force (Figure 3, regression analysis $r=0.97$ ). There was a significant difference $(P=0.0001)$ in the MRI score for the TA between patients with moderate muscle impairment $(\mathrm{MIRS}=3$; MRI score: $3.7 \pm 0.6$, mean \pm S.D., range 0-4) and those with severe muscle impairment (MIRS $=4$; MRI score: $1.8 \pm 1.4$, mean \pm S.D., range 3-5). Finally, there was no significant correlation between the TA MRI score and the duration of the disease $(P=0.3)$ or the number of CTG repeats $(P>0.10)$.

For DM1 patients, there was no significant sex-(multivariate Wilk's lambda statistic, $P=0.16$ ) and age-dependent effect in the number and severity of affected muscles in the legs. There was also no correlation between the total MRI score of the

Table 3: MRI Score of each skeletal muscle for 41 DM1 patients

\begin{tabular}{lcc}
\hline \multicolumn{1}{c}{ Muscles } & Total MRI score & \% of patients with abnormality \\
& & \\
\hline & & 93 \\
Medial gastrocnemius & 134 & 95 \\
Soleus & 127 & 80 \\
Tibialis anterior & 111 & 73 \\
Extensor hallucis longus & 96 & 71 \\
Extensor digitorum longus & 92 & 66 \\
Flexor hallucis longus & 83 & 66 \\
Lateral gastrocnemius & 79 & 59 \\
Peroneus & 68 & 44 \\
Flexor digitorum longus & 35 & 24 \\
Tibialis posterior & 22 & \\
\hline
\end{tabular}

The total MRI score represents the sum of 41 DM1 patients MRI score for each skeletal muscle. For each skeletal muscle, the MRI score was the sum of edema and atrophy/fatty replacement. 


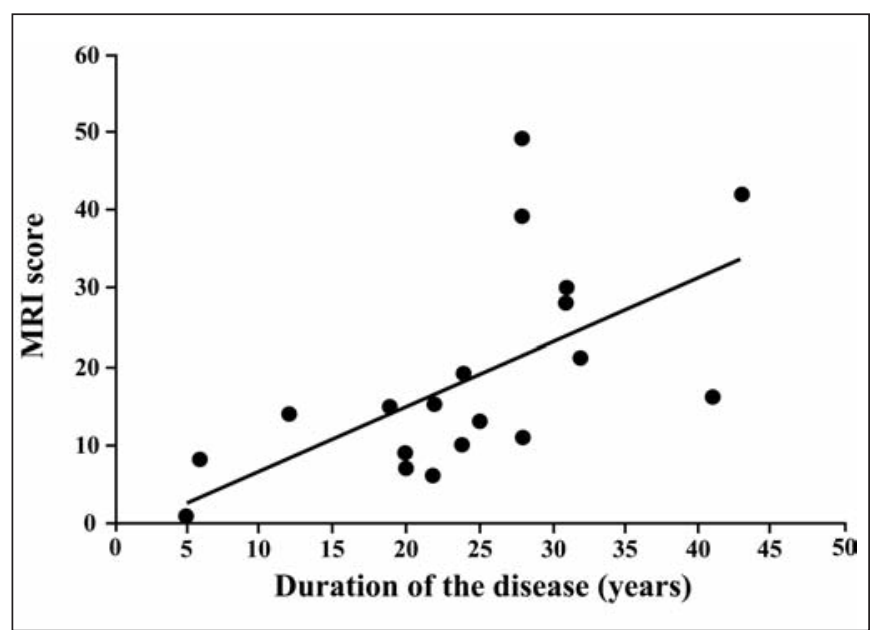

Figure 4: The Total MRI Score of the skeletal muscles of the leg correlated with the duration of the disease in patients with myotonic dystrophy type 1. The total MRI score represent the sum of the score of each skeletal muscle of the leg. $(r=0.62, n=19, P=0.001)$.

skeletal muscles of leg and the number of CTG repeats. There was a significant correlation between the total MRI score of the skeletal muscles of the leg and the duration of the disease $(P<$ 0.01 , Figure 4) and with the severity of skeletal muscles impairment $(P=0.014$, Figure 5).

\section{Discussion}

The histopathological characteristics of DM1 are hallmarked by variations in fiber size, slight necrosis, phagocytosis and fibrosis and the absence of regenerative activity. The aim of this study was to evaluate whether MRI can provide markers of severity of the disease and muscle damage.

Overall, our data agree with previous published data- with some new interesting points. The MRI abnormalities in the TA ranged from the absence of any MRI abnormalities to edema-like abnormalities and/or severe fatty replacement/atrophy. These changes greatly varied from one patient to another. The vast majority of patients (63\%) had edema-like abnormalities in the TA either alone or associated with atrophy and fatty replacement. The significance of edema-like abnormalities is unclear since histopathological findings provided no signs of muscle edema in DM1 muscles. It is unlikely that edema-like abnormalities results from exercise because physical activity was avoided prior to the MRI exam and, on the other hand, edema-like abnormalities are not observed in all other skeletal muscles of the leg in the same patients. Edema-like abnormalities have been found in physiological conditions such fiber type 2 hypertrophy due to strength training ${ }^{16}$. A possibility is that edema-like abnormalities could be relative to type- 2 fiber hypertrophy, a common histological feature observed in DM1 skeletal muscles. If so, this may explain why edema-like abnormalities are predominantly found in the skeletal muscles of the anterior compartment of the leg, which contain fiber type 1 and type 2, whereas the skeletal muscles of the posterior compartment contain predominantly fiber type 1. It is thought that edema-like abnormalities probably

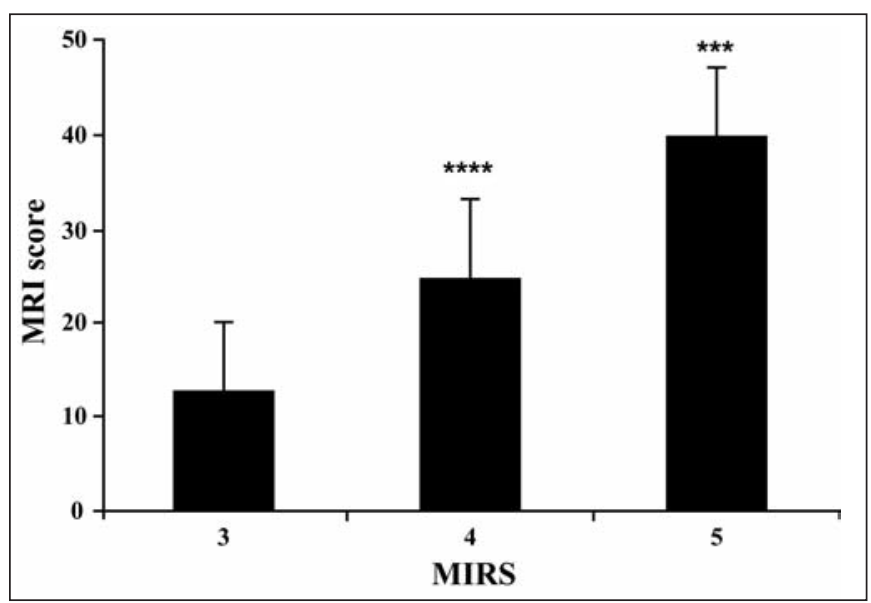

Figure 5: Correlation between the total MRI Score and the Muscular Impairment Rating Scale (MIRS) in patients with DM1. Eighteen (18) patients had a MIRS at 3, 19 DM1 patients had a MIRS at 4 and 4 at 5 . Results are the mean $\pm S D$. Statistical analysis were performed by Student $t$ test $(* * * P=0.0006, * * * * P=0.0001)$.

characterize an early stage of muscle degeneration ${ }^{17}$. This is supported by the decrease in muscle strength observed in two patients with edema-like abnormalities only. In this study we observed a combination of edema-like abnormalities and atrophy of the same muscle, even in some cases of severe atrophy/fatty replacement. We therefore believe that edema-like abnormalities represent more of an active stage of muscle degeneration, suggesting that muscle destruction may not have a linear progression in time. Edema-like abnormalities may be an earlier MRI marker of active muscle degeneration and, it would be of interest to determine whether edema-like abnormalities may be a marker of hypertrophy of fiber type 2 in DM1.

We found a significant correlation between fatty infiltration/ atrophy and TA muscle weakness. In some patients, however, the decreased in the TA muscle strength did not correlate well with MRI changes. Decreases in TA muscle force was observed in patients without any MRI abnormalities, suggesting that decreases in muscle force precedes MRI abnormalities. This agrees with a recent study showing muscle abnormality on clinical examination but not on MRI in 18 muscle groups in other muscular dystrophies ${ }^{8}$. In this latter study, however, muscle MRI abnormalities precede detectable clinical involvement in $50 \%$ of muscle groups. Because muscle groups were not identified, it is therefore possible that strong muscle groups, such as those involved in ankle extension, need some degree of impairment before inducing decrease in muscle force. This may explain how MRI abnormalities may precede clinical impairment for some muscle groups. On the other hand, the absence of MRI abnormalities in patients with decreased power clinically may be related to the mechanism underlying muscle weakness in different muscular dystrophies. Further studies are necessary to clarify this point. We also observed an asymmetry in MRI abnormalities between the right and left TA muscle which are not associated with asymmetry in muscle force suggesting that remaining healthy muscle may compensate for 
the loss of disease fibers at least during the first years of evolution of the disease. Fatty infiltration and atrophy in the TA correlate well with the severity and duration of the disease. This is consistent with findings in a previous study by Bachmann et $\mathrm{al}^{11}$. This indicates that quantification of fatty infiltration and muscle atrophy may represent MRI markers of disease progression and severity.

Even if DM1 is a genetic disorder caused by pathogenic repeat mutations, we did not find a significant correlation between our TA MRI abnormalities and the number of CTG repeats in leukocytes. This is on good agreement with previous report $^{11}$. It is however necessary to keep in mind that the number of the CTG repeats in leukocytes does not reflect the number of CTG repeats in skeletal muscle. We cannot therefore exclude a correlation between the MRI score and the number of CTG repeats in muscles.

\section{Conclusion}

Magnetic resonance imaging appears to be a valuable tool for depicting muscle abnormalities and to help to select skeletal muscles for gene or cell therapy. Finally, muscle MRI is not a reliable indicator of skeletal muscle involvement for DM1 since the decrease in TA muscle force is not correlated with MRI abnormalities in some patients.

\section{ACKNOWLEDGEMENTS}

This work was supported by the Association Française de lutte contre les Myopathies (AFM), France. This work is part of a French-Canadian program on DM1, coordinated by Dr. J.P.

\section{REFERENCES}

1. Harper PS. Myotonic dystrophy- the clinical picture. In: Saunders WB, editor. Myotonic dystrophy, third edition. London: 2001. p. 17-46.

2. Fu YH, Pizzuti A, Fenwick Jr RG, et al. An unstable triplet repeat in a gene related to myotonic muscular dystrophy. Science. 1992;255(5049): 1256-8.

3. Brook JD, McCurrach ME, Harley HG, et al. Molecular basis of myotonic dystrophy: expansion of a trinucleotide (CTG) repeat at the $3^{\prime}$ end of a transcript encoding a protein kinase family member. Cell. 1992;68(4):799-808.

4. Mahadevan M, Tsifidis C, Sabourin L et al. Myotonic dystrophy mutation: an unstable CTG repeat in the 3' untranslated region of the gene. Science. 1992;255(5049):1253-5.

5. Harley HG, Brook JD, Rundle SA, et al. Expansion of unstable DNA region and phenotypic variation in myotonic dystrophy. Nature. 1992;355(6360):545-6.

6. Damian MS, Bachmann G, Herrmann D, Dorndorf W. Magnetic resonance imaging of muscle and brain in myotonic dystrophy. $\mathrm{J}$ Neurol. 1993;240(1):8-12.

10. Castillo J, Pumar JM, Rodriguez JR, et al. Magnetic resonance imaging of muscles in myotonic dystrophy. Eur J Radiol. 1993; 17(3):141-4.

11. Bachmann G, Damian MS, Koch M, Schilling G, Fach B, Stöppler $S$. The clinical and genetic correlates of MRI findings in myotonic dystrophy. Neuroradiology. 1996;38(7):629-35.

12. Kornblum $\mathrm{C}$, Lutterbey $\mathrm{G}$, Bogdanow $\mathrm{M}$, et al. Distinct neuromuscular phenotypes in myotonic dystrophy types 1 and 2 . J Neurol. 2006;253(6):753-61.

13. Stramare R, Beltrame V, Dal Borgo R, et al. MRI in the assessment of muscular pathology: a comparison between limb-girdle muscular dystrophies, hyaline body myopathies and myotonic dystrophies. Radiol Med. 2010;115(4):585-99.

14. Mathieu J, Boivin H, Meunier D, Gaudreault M, Begin P. Assessment of a disease-specific muscular impairment rating scale in myotonic dystrophy. Neurol. 2001;56(3):336-40.

15. Hébert LJ, Remec JF, Saulnier J, Vial C, Puymirat J. The use of muscle strength assessed with handheld dynamometers as noninvasive biological marker in myotonic dystrophy type 1 patients: a multicentric study. BMC Musculoskelet Disord. 2010;18:11-72.

16. Schedel H, Reimers CD, Vogl T, Witt TN. Muscle edema in MR imaging of neuromuscular diseases. Acta Radiol. 1995;36(3): 228-32.

17. Fleckenstein JL. MRI of neuromuscular disease: the basics. Semin Musculoskelet Radiol. 2000;4(4):393-419. 